\title{
MicroRNA-322 attenuates aluminum maltolate-induced apoptosis in the human SH-SY5Y neuroblastoma cell line
}

\author{
XINLONG MA $^{1 *}$, FENG SHANG ${ }^{1 *}$, QIUXIA ZHANG ${ }^{2}$, QINGTANG LIN $^{1}$, SHUO HAN $^{3}$, \\ YONGZHI SHAN $^{1}$, JIANXIN DU ${ }^{1}$, FENG LING ${ }^{1}$, HONGQI ZHANG ${ }^{1}$ and GENG XU ${ }^{1}$ \\ ${ }^{1}$ Department of Neurosurgery, Xuanwu Hospital, Capital Medical University, Beijing 100053; \\ ${ }^{2}$ School of Traditional Chinese Medicine, Capital Medical University, Beijing 100069; \\ ${ }^{3}$ Human Anatomy Division, Hebei Medical University, Shijiazhuang, Hebei 050011, P.R. China
}

Received May 30, 2016; Accepted April 6, 2017

DOI: $10.3892 / \mathrm{mmr} .2017 .6809$

\begin{abstract}
Aluminum-maltolate (Al-Malt) is a potent apoptosis inductor, which has been widely reported as an etiologic factor in Alzheimer's disease (AD). MicroRNA-322 (miR-322) is a vital regulator in various biological processes. The aim of the current study was to identify the role and possible underlying mechanism of miR-322 in Al-Malt-induced apoptosis. Eight concentrations of Al-Malt were prepared and used for treating the human neuroblastoma cell line, SH-SY5Y. Subsequent to treatment with Al-Malt for 3 days, cell viability, apoptosis and the expression levels of apoptosis-associated factors were measured. In addition, the mRNA expression level of miR-322 was monitored. Furthermore, cells were transfected with an miR-322 mimic and/or treated with Al-Malt, and cell viability, apoptosis and the expression levels of apoptosis-associated factors were measured again. Al-Malt significantly inhibited cell viability, but promoted apoptosis. The apoptosis-associated factors, V-Myc avian myelocytomatosis viral oncogene homolog (c-Myc), Bcl-2-associated X protein, caspase- 3 and cleaved caspase- 3 were markedly upregulated by Al-Malt. The mRNA expression level of miR-322 was negatively regulated by Al-Malt. Furthermore, miR-322 attenuated the apoptosis induced by Al-Malt and recovered the expression changes of these four factors. Thus, miR-322 may attenuate Al-Malt-induced apoptosis by recovering the expression change of c-Myc. Furthermore, miR-322 may be involved in the pathogenesis of Al-Malt-associated AD.
\end{abstract}

Correspondence to: Dr Geng Xu, Department of Neurosurgery, Xuanwu Hospital, Capital Medical University, N45 Changchun Street, Xicheng, Beijing 100053, P.R. China

E-mail: xugeng2006@sina.com

*Contributed equally

Key words: microRNA-322, aluminum-maltolate, apoptosis, V-Myc avian myelocytomatosis viral oncogene homolog, Alzheimer's disease

\section{Introduction}

Alzheimer's disease (AD) is a chronic neurodegenerative disorder, that results in the death of nerve cells, deterioration of cognitive function and eventual mortality as a result of complications (1). Furthermore, AD is the most common cause of dementia in older adults with loss of cognitive functions and memory (2). The exact cause of AD is poorly understood, although increasing age, family history and genetics, head injuries and hypertension are recognized as primary risk factors $(3,4)$. In the past several decades, attempts to uncover the underlying mechanism of AD pathogenesis and to further translate these findings into the clinic have been made (5). However, there are no treatments that stop or reverse its progression, and the current therapeutic strategies only temporarily improve symptoms $(2,5)$. Therefore, an improved understanding of $\mathrm{AD}$ may facilitate the diagnosis or treatment of this devastating disease.

Aluminum ( $\mathrm{Al})$ is the third most abundant element in the earth's crust (6). It has been implicated as an etiologic factor in various neuronal diseases, particularly in AD (7-9). Foci of $\mathrm{Al}$ have been detected in the neurofibrillary tangle of $\mathrm{AD}$ patients (10) and Al has been reported as neurotoxic in the central nervous system $(11,12)$. Maltolate (Malt) is a common component of the human diet, contained in coffee, soybeans, baked cereals, and caramelized and browned foods (13). Malt has been reported to be a strong enhancer of $\mathrm{Al}$ accumulation in the brain. Furthermore, numerous studies have demonstrated that, aluminum-maltolate (Al-Malt), the complex of $\mathrm{Al}$ and Malt, is a potent neurotoxin. Furthermore, in vitro and in vivo investigations have elucidated that apoptosis induced by Al-Malt was the major cause of neurotoxicity $(12,14)$. Therefore, inhibition of Al-Malt-induced apoptosis may present a novel strategy to hinder the progression of AD.

MicroRNAs (miRNAs), a class of small non-coding transcripts, regulate gene expression in various physiological and pathological conditions (15). Numerous studies have shown that miRNAs have been used to decode different signaling pathways associated with various types of disease (16). For example, certain miRNAs, such as miR-9 and miR-125b, have been utilized as biomarkers for the diagnosis of early AD (17). Furthermore, various miRNAs have been found to 
be associated with the pathogenesis of $\mathrm{AD}$, and to affect the expression levels and functions of AD-relevant molecules (18). The role of miRNAs in neuronal apoptosis in AD has previously been investigated. Absalon et al (19) demonstrated that miR-26b activated apoptosis in post-mitotic neurons, and inhibition of miR-26b was a novel strategy for neuroprotection. Zhang et al (20) found that inhibition of miR-16 in the cellular AD model with primary hippocampal neurons increased apoptosis. However, whether various miRNAs, including miR-322, are involved in Al-Malt-induced apoptosis in neural cells, has not yet been well investigated.

Therefore, the aim of the present study was to investigate the role of miR-322 in Al-Malt-induced apoptosis in neural cells. The human SH-SY5Y neuroblastoma cell line was used to induce apoptosis in vitro by treatment with eight concentrations of Al-Malt. Cell viability, apoptosis and its associated factors were determined to investigate the role of Al-Malt in neural cell apoptosis and its associated mechanism. Subsequently, cells were transfected with miR-322 mimics and/or treated with Al-Malt, and the changes in cell viability, apoptosis and the associated factors were measured again to reveal the role of miR-322 in Al-Malt-induced apoptosis. These findings may provide a basic understanding of the mechanism of Al-Malt-associated neurodegenerative pathogenesis.

\section{Materials and methods}

Cell culture. The human SH-SY5Y neuroblastoma cell line, a cell line that is commonly used for researching neurotoxicity and neurodegenerative diseases (14), was purchased from the American Type Culture Collection (Manassas, VA, USA). Cells were cultured in Dulbecco's modified Eagle's medium (DMEM; GE Healthcare Life Sciences, Logan, UT, USA) supplemented with $10 \%$ fetal bovine serum (FBS; GE Healthcare Life Sciences) and maintained in a humidified atmosphere at $37^{\circ} \mathrm{C}$ with $5 \% \mathrm{CO}_{2}(21)$.

Al-Malt preparation. Al-Malt was prepared as previously described in detail (22). Al-Malt was dissolved in DMEM containing $10 \%$ FBS (12) to establish eight concentrations of Al-Malt $(0,0.01,0.05,0.1,0.25,0.5,1$ and $2 \mathrm{mM})$. Prior to Al-Malt treatment, the eight Al-Malt concentrations were adjusted to a $\mathrm{pH}$ of 7.4 and filtered through a $0.22-\mu \mathrm{m}$ pore filter.

Cell viability. Cell viability was assessed using the 3-(4,5-dimethyl-2-thiazolyl)-2,5-diphenyltetrazolium bromide (MTT) assay. Briefly, cells were seeded in 96-well plates at a density of $2 \times 10^{3}$ cells/well. After $12 \mathrm{~h}$ of incubation at $37^{\circ} \mathrm{C}$, cells were treated with the eight concentrations of Al-Malt (0-2 mM) for 3 days. Al-Malt with $0 \mathrm{mM}$ served as a blank control. Subsequently, $0.5 \mathrm{mg} / \mathrm{ml}$ MTT solution (Sigma Aldrich; Merck KGaA, Darmstadt, Germany) was added to each well, and incubated for another $3 \mathrm{~h}$ at $37^{\circ} \mathrm{C}$. Finally, formazan was dissolved in dimethyl sulfoxide (DMSO) and the absorbance was recorded with a Multiskan EX (Thermo Fisher Scientific, Inc., Waltham, MA, USA) at a wavelength of $570 \mathrm{~nm}(23)$.

Cell apoptosis. Cell apoptosis was evaluated using an Annexin V/fluorescein isothiocyanate (FITC) and propidium iodide (PI) apoptosis detection kit (BD Biosciences, Franklin Lakes, NJ, USA). Briefly, cells were pre-treated with $0.25,0.5$ and $1 \mathrm{mM}$ concentrations of Al-Malt for 3 days at $37^{\circ} \mathrm{C}$, and cells were collected and suspended in Annexin-binding buffer. Cells were first stained with Annexin V-FITC for $30 \mathrm{~min}$, and subsequently stained with PI for $10 \mathrm{~min}$, in the dark at room temperature. The percentage of apoptotic cells was immediately assessed by flow cytometry (BD Biosciences).

Western blot analysis. Following 3 days of Al-Malt treatment, cellular protein was extracted using lysis buffer (Beyotime Institute of Biotechnology, Shanghai, China) and equal quantities of protein samples $(100 \mu \mathrm{g})$ were separated on $10-12 \%$ sodium dodecyl sulfate-polyacrylamide gels and transferred to nitrocellulose membranes (Whatman $\mathrm{GmbH}$, Dassel, Germany). After blocking with 5\% skimmed milk for $1 \mathrm{~h}$ at room temperature, the membranes were incubated with the appropriate primary antibodies (all at a dilution of 1:1,000) overnight at $4^{\circ} \mathrm{C}$. Anti-Actin (no. 8457) and anti-Bcl-2-associated X protein (Bax) (no. 5023) were purchased from Cell Signaling Technology, Inc. (Danvers, MA, USA). Anti-V-Myc avian myelocytomatosis viral oncogene homolog (c-Myc) (ab32072), anti-caspase-3 (ab13585) and anti-cleaved caspase-3 (ab32042) were obtained from Abcam (Cambridge, USA). Actin served as a loading control. Subsequently, the membranes were incubated with a horseradish peroxidase-conjugated secondary antibody (anti-mouse IgG, ab6728; anti-rabbit IgG, ab6721) (Abcam) diluted 1:2,000, for $2 \mathrm{~h}$ at room temperature. Protein bands were visualized using the WEST-ZOL-plus Western Blot Detection System (Intron Biotechnology, Inc., Seongnam, Korea). Optical density was calculated by ImageJ software version 1.49 (National Institutes of Health, Bethesda, MD, USA).

Reverse transcription-quantitative polymerase chain reaction $(R T-q P C R)$. Total RNA was isolated from cells using TRIzol reagent-phenol chloroform (Thermo Fisher Scientific, Inc.), and synthesis of cDNA was performed using a Transcriptor First Strand cDNA Synthesis kit (Roche Applied Science, Madison, WI, USA), according to the manufacturer's instructions. FastStart Universal SYBR-Green Master (ROX) (Roche Applied Science) was used for the analysis, and 20- $\mu$ l reaction mixtures were performed on an ABI PRISM 7500 Real-time PCR system (Applied Biosystems; Thermo Fisher Scientific, Inc.). The results were analyzed using the $2^{-\Delta \Delta C q}$ method (24), and were normalized to U6 snRNA. The miRNA primers were purchased from Shanghai GenePharma Co., Ltd. (Shanghai, China).

Cell transfection. Cells were seeded in 6-well plates at a density of $5 \times 10^{4} /$ well. After reaching $\sim 60 \%$ confluence, cells were transfected with miR-322 mimic or control (Shanghai GenePharma Co., Ltd.) using Lipofectamine RNAiMAX reagent (Thermo Fisher Scientific, Inc.) according to the manufacturer's instructions. After a 48-h transfection, cells were collected for subsequent experimentation.

Statistical analysis. All data are presented as the mean \pm standard deviation from three independent experiments and 
A

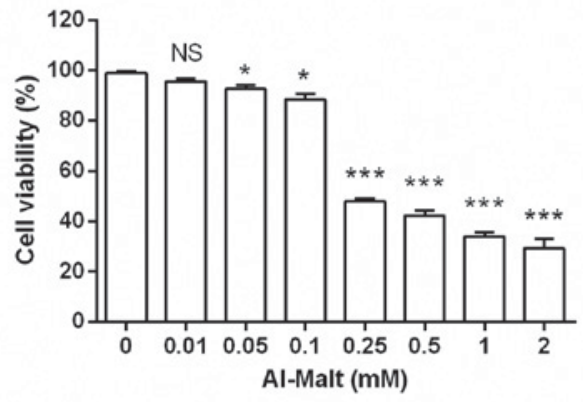

C

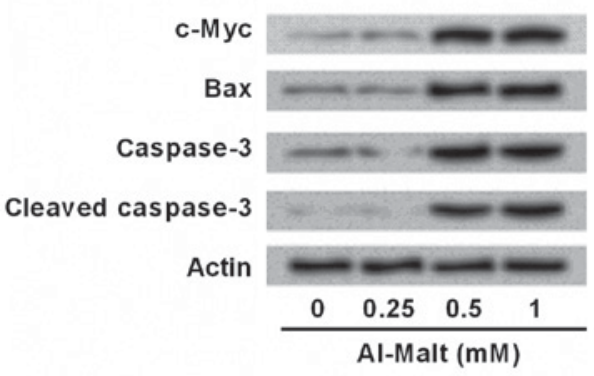

B

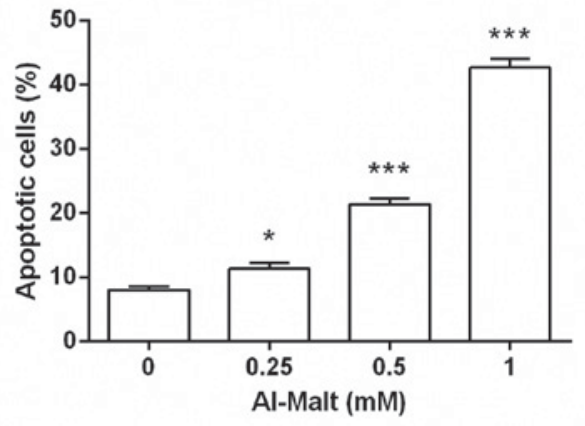

D

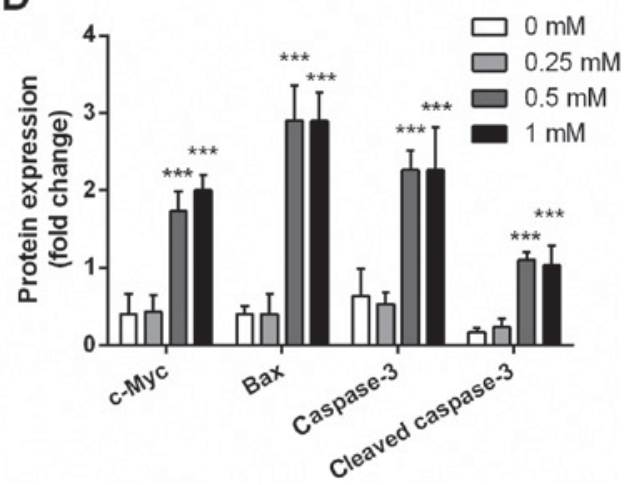

Figure 1. Al-Malt induced SH-SY5Y cell apoptosis by regulating the expression level of c-Myc. Different concentrations of Al-Malt (0-2 mM) were used for treating the SH-SY5Y cells. Following 3 days of treatment, cell viability and apoptosis were determined by (A) 3-(4,5-dimethyl-2-thiazolyl)-2,5-diphenyltetrazolium bromide assay and (B) flow cytometry. The changes of c-Myc, Bax, caspase-3 and cleaved caspase-3 expression levels in the cells were measured by (C) western blotting. (D) Quantitative analysis of western blot results. Values represent the mean \pm standard deviation. ${ }^{*} \mathrm{P}<0.05$ and ${ }^{* * *} \mathrm{P}<0.001$ vs. $0 \mathrm{mM}$. Al-Malt, aluminum-maltolate; c-Myc, V-Myc avian myelocytomatosis viral oncogene homolog; Bax, Bcl-2-associated X protein; NS, no significance.

analyses. Statistical analyses were performed using SPSS version 13.0 (SPSS, Inc., Chicago, IL, USA), and differences were analyzed by one-way analysis of variance followed by Dunnett's test. $\mathrm{P}<0.05$ was considered to indicate a statistically significant difference.

\section{Results}

Al-Malt induced cell apoptosis by regulating the expression levels of $c-M y c$. To investigate the functional role of Al-Malt in neural cell apoptosis, eight concentrations of Al-Malt (0-2 mM) were prepared and used for treating SH-SY5Y cells. After 3 days of treatment, cell viability and apoptosis were determined by MTT assay (Fig. 1A) and flow cytometry (Fig. 1B). Al-Malt was demonstrated to significantly decrease cell viability $(\mathrm{P}<0.05$ and $\mathrm{P}<0.001)$ and increase apoptosis $(\mathrm{P}<0.05$ and $\mathrm{P}<0.001)$, compared with the control group. Higher concentrations of Al-Malt led to stronger cell viability inhibitive and apoptosis inductive effects. These results revealed that Al-Malt induced cell apoptosis in a dose-dependent manner. In addition, three of the higher concentrations of Al-Malt $(0.25$, 0.5 and $1 \mathrm{mM}$ ) were selected for the further investigation.

To investigate the possible underlying mechanism of Al-Malt-induced apoptosis, the expression changes of c-Myc, Bax, caspase- 3 and cleaved caspase- 3 in cells were evaluated by western blotting. As shown in Fig. $1 \mathrm{C}$ and $\mathrm{D}$, the protein expression levels of c-Myc, Bax, caspase-3 and cleaved caspase- 3 were markedly upregulated by 0.5 and $1 \mathrm{mM}$ concentrations of Al-Malt (all $\mathrm{P}<0.001)$. Therefore, it was

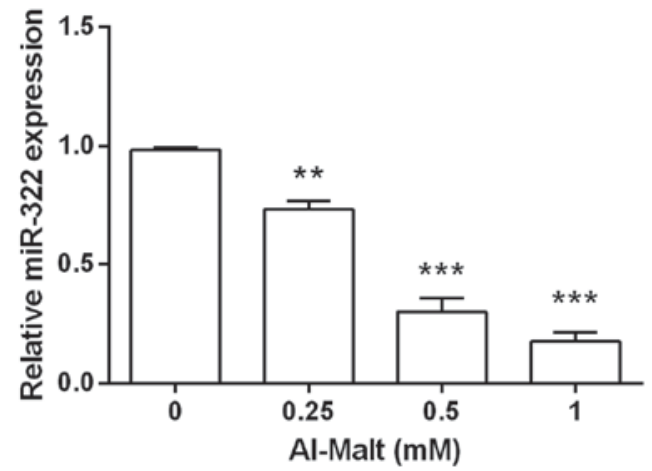

Figure 2. miR-322 was negatively regulated by Al-Malt. SH-SY5Y cells were pre-treated with Al-Malt $(0.25,0.5$ and $1 \mathrm{mM})$ and the expression level of miR-322 mRNA was analyzed by reverse transcription-quantitative polymerase chain reaction. Values represent the mean \pm standard deviation. ${ }^{* *} \mathrm{P}<0.01$ and ${ }^{* * *} \mathrm{P}<0.001$ vs. $0 \mathrm{mM}$. Al-Malt, aluminum-maltolate; miR, microRNA.

inferred that Al-Malt induced SH-SY5Y cell apoptosis via regulating c-Myc, Bax and caspase-3.

MiR-322 was negatively regulated by Al-Malt. To establish whether miR-322 was involved in the apoptosis induced by Al-Malt, SH-SY5Y cells were pre-treated with Al-Malt, and the level of miR-322 mRNA expression was evaluated by RT-PCR analysis (Fig. 2). Compared with the control group, the mRNA level of miR-322 expression was significantly downregulated by Al-Malt $(\mathrm{P}<0.01$ and $\mathrm{P}<0.001)$. Furthermore, 
A

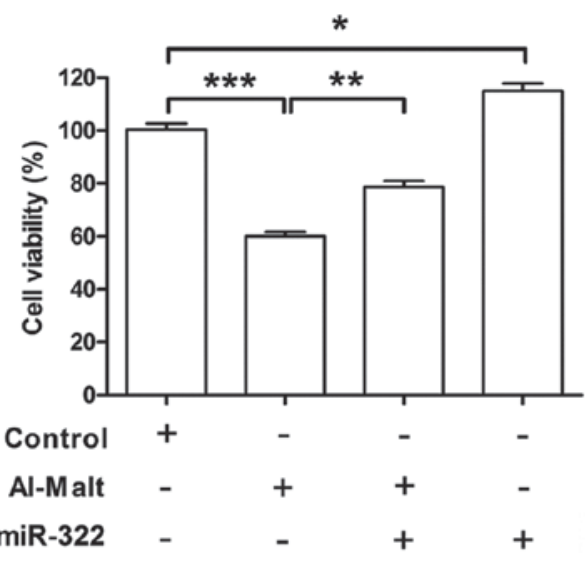

C

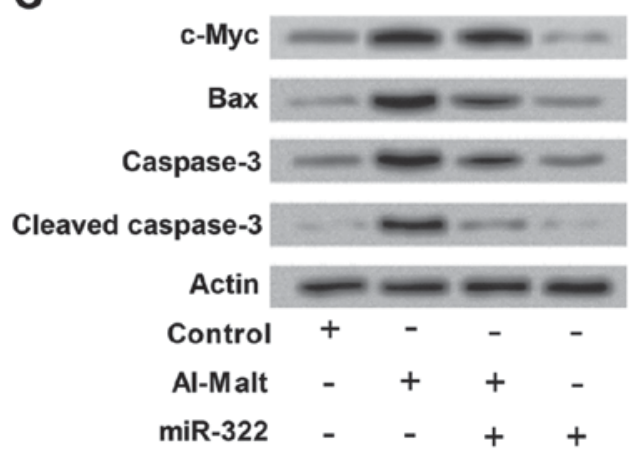

B


Figure 3. miR-322 attenuated Al-Malt-induced apoptosis by recovering the expression level changes of c-Myc. SH-SY5Y cells were transfected with miR-322 mimic and/or treated with $1 \mathrm{mM} \mathrm{Al-Malt,} \mathrm{and} \mathrm{the} \mathrm{cell} \mathrm{viability,} \mathrm{apoptosis} \mathrm{and} \mathrm{expression} \mathrm{level} \mathrm{changes} \mathrm{of} \mathrm{its} \mathrm{associated} \mathrm{factors} \mathrm{were} \mathrm{measured} \mathrm{by}$ (A) 3-(4,5-dimethyl-2-thiazolyl)-2,5-diphenyltetrazolium bromide assay, (B) flow cytometry and (C) western blot analysis. (D) Quantitative analysis of western blot results. Values represent the mean \pm standard deviation. ${ }^{*} \mathrm{P}<0.05,{ }^{* *} \mathrm{P}<0.01$ and ${ }^{* * *} \mathrm{P}<0.001$. miR, microRNA; Al-Malt, aluminum-maltolate; c-Myc, V-Myc avian myelocytomatosis viral oncogene homolog; Bax, Bcl-2-associated X protein; NS, no significance.

a higher concentration of Al-Malt exerted a stronger suppressive effect on miR-322. Thus, it was inferred that miR-322 may be a pivotal gene in Al-Malt-induced apoptosis, and miR-322 may be negatively regulated by Al-Malt. In addition, a 1-mM concentration of Al-Malt was selected for the following investigation.

MiR-322 attenuated Al-Malt-induced apoptosis by recovering the expression changes of $c-M y c$. To determine the role of miR-322 in Al-Malt-induced apoptosis, cells were transfected with miR-322 mimic and/or treated with $1 \mathrm{mM}$ Al-Malt. Cell viability and apoptosis were subsequently measured by MTT assay (Fig. 3A) and flow cytometry (Fig. 3B). As expected, Al-Malt significantly inhibited cell viability $(\mathrm{P}<0.001)$ and promoted apoptosis $(\mathrm{P}<0.001)$, whereas miR-322 overexpression exhibited the completely opposite effect (All $\mathrm{P}<0.05$ ). Notably, miR-322 overexpression significantly attenuated the inhibitive cell viability and inductive apoptotic effects of Al-Malt $(\mathrm{P}<0.01$ and $\mathrm{P}<0.001)$. Therefore, it was proposed that miR-322 attenuated Al-Malt-induced apoptosis.

To further investigate the possible underlying mechanism of miR-322 attenuated Al-Malt-induced apoptosis, and expression changes of c-Myc, Bax, caspase-3 and cleaved caspase-3 in SH-SY5Y cells were detected by western blotting. Al-Malt markedly upregulated the expression levels of c-Myc, Bax, caspase-3 and cleaved caspase-3 (all $\mathrm{P}<0.001$, Fig. 3C and D). miR-322 slightly downregulated these four factors, however the downregulatory impact of miR-322 on these proteins did not reach statistical significance $(\mathrm{P}>0.05)$. However, miR-322 overexpression was able to ameliorate Al-Malt-induced changes in the expression levels of these factors. Therefore, miR-322 attenuated Al-Malt-induced apoptosis by recovering the expression changes of these factors.

\section{Discussion}

miRNA research has become popular in AD studies, although the role of miRNAs in Al-Malt-induced apoptosis remains unclear. In the current study, the human neuroblastoma cell line, SH-SY5Y was used to induce apoptosis by treatment with different concentrations of Al-Malt for 3 days. It was identified that Al-Malt induced cell apoptosis by regulating the expression levels of c-Myc, Bax and caspase-3. Furthermore, Al-Malt negatively regulated the expression level of miR-322. miR-322 attenuated the apoptosis Al-Malt-induced by recovering the expression changes of c-Myc, Bax and caspase-3.

As a potent neurotoxin, Al-Malt has been widely investigated for its neurotoxicity in various types of nervous system 
disease. Increasing evidence has demonstrated that Al-Malt exerted its neurotoxic effects by inducing neural cell apoptosis. Savory et al (25) demonstrated that, in the hippocampus of rabbits, Al-Malt induced apoptosis by perturbing the ratio of Bcl-2: Bax. More recently, experiments in rat brain tissue samples showed that Al-Malt induced neural cell apoptosis by altering the AKT/p53 signaling pathway (14). Partly consistent with these previous studies, the present findings indicate that Al-Malt is a powerful neurotoxin for inducing neural cell apoptosis. However, the current study provides a novel insight into the mechanism by which Al-Malt induced apoptosis, demonstrating that the progression of apoptosis was associated with expression level changes of c-Myc.

The proto-oncogene, c-Myc is a Myc family member, which performs a pivotal function in growth control, differentiation and apoptosis (26). In the past several decades, the role of c-Myc in apoptosis has been extensively investigated. c-Myc has been reported as a vital factor in cell apoptosis induction. For example, in interleukin (IL)-3-dependent myeloid cells, c-Myc was demonstrated to induce or sensitize cells to apoptosis (27). In rat fibroblasts, deregulating the expression of c-Myc resulted in cell death by apoptosis (28). Furthermore, studies have established that the mitochondrial apoptotic pathway participates in c-Myc-mediated apoptosis, and the pro-apoptotic factor, Bax is also involved (26). Using a switchable mouse model of c-Myc-induced apoptosis in pancreatic $\beta$-cells, c-Myc induced apoptosis in vivo by regulating Bax (29). Notably, c-Myc amplifies apoptosis signaling at the mitochondria by controlling the caspase feedback amplification loop; a process of effector caspases, caspase-3 and caspase-7, which activate caspase-8 (26). Taken together, c-Myc exerts a pivotal role in apoptosis induction by regulating Bax and caspases. In the current study, the expression levels of c-Myc, Bax, caspase-3 and cleaved caspase-3 were markedly upregulated by Al-Malt. Therefore, it was hypothesized that Al-Malt induced apoptosis by regulating the expression level of c-Myc.

miR-322 is an miRNA located on chromosome $\mathrm{X}$, which is abundantly expressed in various types of species (30). miR-322 has previously been investigated as a vital regulator in the cell cycle, and cell proliferation, formation and differentiation $(31,32)$. However, the role of miR-322 in cell apoptosis has not been well investigated. In a study by Cao et al (30) miR-322 served as an apoptosis inductor in intestinal epithelial cells; silencing miR-322 together with miR-503 resulted in the repression of apoptosis. However, Gu et al (33) demonstrated miR-322 as an apoptosis inhibitor in neural stem cells. miR-322 was negatively regulated by maternal diabetes and high glucose, which was implicated in high glucose-induced apoptosis by activating caspases (33). The current findings were partly consistent with the study by Gu et al (33) that miR-322 overexpression inhibited cell apoptosis. In addition, miR-322 was negatively regulated by Al-Malt, and attenuated the apoptosis induced by Al-Malt via recovering the expression level change of c-Myc.

In conclusion, the present study is the first, to the best of our knowledge, to demonstrate that Al-Malt induced cell apoptosis by upregulating protein expression levels of c-Myc. miR-322 attenuates the apoptosis induced by Al-Malt, thus miR-322 may be involved in the pathogenesis of Al-Malt-associated AD.

\section{Acknowledgements}

The present study was supported by the fund for the science and technology activities of excellent overseas students in 2015 (Ministry of Human Resources and Social Security; grant no. 008-0064) and the Basic and Clinical Research Project Foundation of Capital Medical University (grant no. 303-01-007-0132).

\section{References}

1. Chopra K, Misra S and Kuhad A: Neurobiological aspects of Alzheimer's disease. Expert Opin Ther Targets 15: 535-555, 2011.

2. Sung HY, Choi BO, Jeong JH, Kong KA, Hwang J and Ahn JH: Amyloid beta-mediated hypomethylation of heme oxygenase 1 correlates with cognitive impairment in Alzheimer's disease. PLoS One 11: e0153156, 2016.

3. Puthiyedth N, Riveros C, Berretta R and Moscato P: Identification of differentially expressed genes through integrated study of Alzheimer's disease affected brain regions. PLoS One 11: $\mathrm{e} 0152342,2016$.

4. Scheltens P, Blennow K, Breteler MM, de Strooper B, Frisoni GB, Salloway S and Van der Flier WM: Alzheimer's disease. Lancet 388: 505-517, 2016.

5. Zheng C, Zhou XW and Wang JZ: The dual roles of cytokines in Alzheimer's disease: update on interleukins, TNF- $\alpha$, TGF- $\beta$ and IFN- $\gamma$. Transl Neurodegener 5: 7, 2016.

6. Lévesque L, Mizzen CA, McLachlan DR and Fraser PE: Ligand specific effects on aluminum incorporation and toxicity in neurons and astrocytes. Brain Res 877: 191-202, 2000.

7. Wills MR and Savory J: Aluminium poisoning: Dialysis encephalopathy, osteomalacia, and anaemia. Lancet 2: 29-34, 1983.

8. Garruto RM: Pacific paradigms of environmentally-induced neurological disorders: Clinical, epidemiological and molecular perspectives. Neurotoxicology 12: 347-377, 1991.

9. Khachaturian ZS: Diagnosis of Alzheimer's disease. Arch Neurol 42: 1097-1105, 1985.

10. Perl DP and Brody AR: Alzheimer's disease: X-ray spectrometric evidence of aluminum accumulation in neurofibrillary tangle-bearing neurons. Science 208: 297-299, 1980.

11. Sánchez-Iglesias S, Méndez-Alvarez E, Iglesias-González J, Muñoz-Patiño A, Sánchez-Sellero I, Labandeira-García JL and Soto-Otero R: Brain oxidative stress and selective behaviour of aluminium in specific areas of rat brain: Potential effects in a 6-OHDA-induced model of Parkinson's disease. J Neurochem 109: 879-888, 2009

12. Johnson VJ, Kim SH and Sharma RP: Aluminum-maltolate induces apoptosis and necrosis in neuro-2a cells: Potential role for p53 signaling. Toxicol Sci 83: 329-339, 2005.

13. Gralla EJ, Stebbins RB, Coleman GL and Delahunt CS: Toxicity studies with ethyl maltol. Toxicol Appl Pharmacol 15: 604-613, 1969.

14. Zhu M, Huang C, Ma X, Wu R, Zhu W, Li X, Liang Z, Deng F, Zhu J, Xie W, et al: Modulation of miR-19 in aluminum-induced neural cell apoptosis. J Alzheimers Dis 50: 1149-1162, 2016.

15. Qin W, Xie W, Yang X, Xia N and Yang K: Inhibiting microRNA-449 attenuates cisplatin-induced injury in NRK-52E cells possibly via regulating the SIRT1/P53/BAX pathway. Med Sci Monit 22: 818-823, 2016.

16. Ardekani AM and Naeini MM: The role of microRNAs in human diseases. Avicenna J Med Biotechnol 2: 161-179, 2010.

17. Lukiw WJ: Micro-RNA speciation in fetal, adult and Alzheimer's disease hippocampus. Neuroreport 18: 297-300, 2007.

18. Zhang C, Lu J, Liu B, Cui Q and Wang Y: Primate-specific miR-603 is implicated in the risk and pathogenesis of Alzheimer's disease. Aging (Albany NY) 8: 272-290, 2016.

19. Absalon S, Kochanek DM, Raghavan V and Krichevsky AM: MiR-26b, upregulated in Alzheimer's disease, activates cell cycle entry, tau-phosphorylation, and apoptosis in postmitotic neurons. J Neurosci 33: 14645-14659, 2013.

20. Zhang B, Chen CF, Wang AH and Lin QF: MiR-16 regulates cell death in Alzheimer's disease by targeting amyloid precursor protein. Eur Rev Med Pharmacol Sci 19: 4020-4027, 2015.

21. Modi PK, Jaiswal S and Sharma P: Regulation of neuronal cell cycle and apoptosis by MicroRNA 34a. Mol Cell Biol 36: 84-94, 2015. 
22. Bertholf RL, Herman MM, Savory J, Carpenter RM, Sturgill BC, Katsetos CD, Vandenberg SR and Wills MR: A long-term intravenous model of aluminum maltol toxicity in rabbits: Tissue distribution, hepatic, renal, and neuronal cytoskeletal changes associated with systemic exposure. Toxicol Appl Pharmacol 98: 58-74, 1989.

23. Lu L, Li C, Li D, Wang Y, Zhou C, Shao W, Peng J, You Y, Zhang $X$ and Shen $X$ : Cryptotanshinone inhibits human glioma cell proliferation by suppressing STAT3 signaling. Mol Cell Biochem 381: 273-282, 2013.

24. Livak KJ and Schmittgen TD: Analysis of relative gene expression data using real-time quantitative PCR and the 2(-Delta Delta C(T)) Method. Methods 25: 402-408, 2001.

25. Savory J, Rao JK, Huang Y, Letada PR and Herman MM: Age-related hippocampal changes in Bcl-2: Bax ratio, oxidative stress, redox-active iron and apoptosis associated with aluminum-induced neurodegenerati: Increased susceptibility with aging. Neurotoxicology 20: 805-817, 1999.

26. Hoffman B and Liebermann DA: Apoptotic signaling by c-MYC. Oncogene 27: 6462-6472, 2008.

27. Askew DS, Ashmun RA, Simmons BC and Cleveland JL: Constitutive c-myc expression in an IL-3-dependent myeloid cell line suppresses cell cycle arrest and accelerates apoptosis. Oncogene 6: 1915-1922, 1991.
28. Evan GI, Wyllie AH, Gilbert CS, Littlewood TD, Land H, Brooks M, Waters CM, Penn LZ and Hancock DC: Induction of apoptosis in fibroblasts by c-myc protein. Cell 69: 119-128, 1992.

29. Dansen TB, Whitfield J, Rostker F, Brown-Swigart L and Evan GI: Specific requirement for Bax, not Bak, in Myc-induced apoptosis and tumor suppression in vivo. J Biol Chem 281: 10890-10895, 2006.

30. Cao S, Xiao L, Rao JN, Zou T, Liu L, Zhang D, Turner DJ, Gorospe $\mathrm{M}$ and Wang JY: Inhibition of Smurf 2 translation by miR-322/503 modulates TGF- $\beta /$ Smad 2 signaling and intestinal epithelial homeostasis. Mol Biol Cell 25: 1234-1243, 2014.

31. Gámez B, Rodríguez-Carballo E, Bartrons R, Rosa JL and Ventura F: MicroRNA-322 (miR-322) and its target protein Tob2 modulate osterix (Osx) mRNA stability. J Biol Chem 288: 14264-14275, 2013.

32. Merlet E, Atassi F, Motiani RK, Mougenot N, Jacquet A, Nadaud S, Capiod T, Trebak M, Lompré AM and Marchand A: miR-424/322 regulates vascular smooth muscle cell phenotype and neointimal formation in the rat. Cardiovasc Res 98: 458-468, 2013.

33. Gu H, Yu J, Dong D, Zhou Q, Wang JY and Yang P: The miR-322-TRAF3 circuit mediates the pro-apoptotic effect of high glucose on neural stem cells. Toxicol Sci 144: 186-196, 2015. 